\title{
Multivariate Normal Distribution
}

National Cancer Institute

\section{Source}

National Cancer Institute. Multivariate Normal Distribution. NCI Thesaurus. Code C53218.

A normal distribution which models more than one variable of interest. The parameters of the multivariate normal distribution include the mean and variance of each individual variable and the correlations between variables. 